Bond University

Research Repository

\title{
Reported load carriage injuries of the Australian Army soldier
}

Orr, Robin M.; Johnston, Venerina; Coyle, Julia; Pope, Rodney

Published in:

Journal of Occupational Rehabilitation

DOI:

10.1007/s10926-014-9540-7

Link to output in Bond University research repository.

Recommended citation(APA):

Orr, R. M., Johnston, V., Coyle, J., \& Pope, R. (2015). Reported load carriage injuries of the Australian Army soldier. Journal of Occupational Rehabilitation, 25(2), 316-322. [7]. https://doi.org/10.1007/s10926-014-9540-7

\section{General rights}

Copyright and moral rights for the publications made accessible in the public portal are retained by the authors and/or other copyright owners and it is a condition of accessing publications that users recognise and abide by the legal requirements associated with these rights.

For more information, or if you believe that this document breaches copyright, please contact the Bond University research repository coordinator. 


\title{
Reported Load Carriage Injuries of the Australian Army Soldier
}

\author{
${ }^{1}$ Dr Robin M Orr, ${ }^{2}$ Dr Venerina Johnston, ${ }^{3}$ Dr Julia Coyle \& ${ }^{1}$ Dr Rodney Pope \\ ${ }^{1}$ Bond University \\ ${ }^{2}$ The University of Queensland \\ ${ }^{3}$ Charles Sturt University
}

\section{Short FormTitle:}

Load Carriage Injuries of ARA Soldiers

\section{Key words:}

Load carriage; soldier; injuries; army

\section{Corresponding Author:}

\section{A/Prof Robin M Orr}

Bond Institute of Health and Sport

Bond University

Gold Coast, QLD 4226

Ph: 61 (0) 755954448

Mob: 61 (0) 468646027 Email: rorr@bond.edu.au

\begin{abstract}
Introduction. Many injuries experienced by soldiers can be attributed to the occupational loads they are required to carry. Purpose: The aim of this study was to determine whether contemporary military load carriage is a source of injuries to Australian Regular Army soldiers and to profile these injuries.

Methods: The Australian Defence Force 'Occupational Health, Safety and Compensation Analysis and Reporting' database was searched to identify all reported injuries sustained during load carriage events. Key search terms were employed and narrative description fields were interrogated to increase data accuracy.

Results: A total of 1,954 injury records were extracted from the database. Of these, 404 injuries were attributed to load carriage. The majority of these load carriage injuries involved either the lower limb or back, with bones and joints accounting for the most frequently reported body structures to be injured. Field activities were the leading activities being performed at the time that load carriage injuries occurred, and muscular stress was identified as the mechanism of injury for over half of reported load carriage injuries.

Conclusion: This study suggests that load carriage is a substantial source of injury risk to Australian Army soldiers. Physical Training may fail to adequately prepare soldiers for load carriage tasks during field training exercises.
\end{abstract}




\section{INTRODUCTION}

Military soldiers are required to carry loads as part of their occupation. These occupational loads protect and sustain soldiers during tasks which are often performed in unpredictable and hostile environments (1). While task dependent, the cumulative impact of these stores and equipment can result in soldiers carrying loads of around $50 \mathrm{~kg}$ on military operations (1). Furthermore, history suggests that the absolute loads being carried by soldiers are increasing $(1,2)$.

As the weight of an occupational load increases so too does the physiological cost of carrying the load (2). In addition, increases in load weight have been found to alter biomechanical aspects of gait and posture, which includes altering the shape of the load carrier's spine (3). As such, load carriage tasks place additional stress on the musculoskeletal system of the carrier (4) creating a risk for musculoskeletal injury (5). Apart from financial costs associated with the treatment of injuries, injuries sustained during load carriage impact on the occupational capacity of the military to recruit and train a soldier and to maintain a combat ready soldier (6). During combat operations, soldier injuries can reduce the combat effectiveness of a unit $(6,7)$.

The impacts of load carriage injuries on military operations can be seen throughout history(1). Circa 400 BC, the long marches of Cyrus' infamous 10,000 left many Greek mercenaries suffering from stress fractures, torn ligaments, muscle damage, blisters and abrasions, the results of which were life threatening as they hobbled to keep up with the moving army (8). During the Franco-Prussian War in 1870, the Prussian Guards left the Rhine with 30,000 soldiers but following weeks of marching lost 12,000 fighting men from fatigue induced by carrying heavy loads. These losses were greater than the number suffered in actual combat 
(9). During the Second World War D-Day landings at Omaha Beach (1944), the American troops were so overloaded that their loads were attributed with causing deaths in the water (10). In 1983, US soldiers assaulting an airhead in Grenada were so overloaded that one soldier describes seeing '... all those guys sitting on the side of the road with IV tubes in them. There's no way the guys could [have gone on]' (10).

Given this history, preventing load carriage injuries is of great importance to any military force. Injury prevention strategies may make a given military force more effective than that same force would be without it (7). However, if effective injury prevention strategies are to be developed to mitigate the risks of injuries associated with the occupational load carriage tasks of soldiers, an understanding of the profile of these injuries is needed. The aim of this study was to determine whether contemporary military load carriage is a source of injuries to Australian Regular Army soldiers and to profile these injuries.

\section{METHODS}

The Australian Defence Force Occupational Health, Safety and Compensation Analysis and Reporting (OHSCAR) database was searched to identify all reported injuries sustained during load carriage events over the period 01 January 2009 to 31 December 2010. In this instance a 'load carriage event' was considered any activity where the soldier reported wearing webbing equipment, body armour or backpack with a 'load carriage injury' defined as an injury occurring during a load carriage event. The OHSCAR database is designed to capture all forms submitted in the notification and reporting of Occupational Health and Safety (OHS) incidents (11) defined here as any accident or event that arises from the performance of Defence work. 
In the current study, the narrative description fields were used as the search medium to identify OHSCAR records of interest, rather than the Type of Occurrence Classification System (TOOCS) data fields. The TOOCS data fields were disregarded as the TOOCS protocol codes incidents by the 'most serious injury or disease sustained'(12). For example, a hand laceration suffered by a soldier who trips over while carrying a heavy load and lacerates his hand on a rock would be coded as a laceration. Second, the TOOCS activity field lacks the specificity required for this study as there are no load carriage codes detailing that the soldier was wearing or carrying a load at the time of injury, and searches of this field were likely to return results that were misleading or not valid. As an example, the TOOCS activity code 'marching' includes incidents arising during 'military drill', 'marching on parade', 'marching as a formed body', and 'endurance marching'. For these two reasons the narrative description fields of incident records was searched rather than the TOOCS-related fields.

The search terms used to search the narrative description fields were those commonly associated with contemporary military load carriage in the ARA. These terms were; 'pack', 'webbing', 'patrol', 'patrol order', 'march', 'marching order', 'route march', 'endurance march', 'Combat Fitness Assessment', 'CFA', 'load', 'load carriage' and 'carry'. Data were collected for a 24-month period (2009 and 2010). Total ARA injury figures reported over this period were also requested.

\section{Data Extraction}

The raw OHSCAR incident data were manually cleaned to ensure that only records of incidents relating to contemporary military load carriage were retained. Each line of data was reviewed, with duplicate entries (same record entered twice) and records unrelated to load carriage (e.g. the term 'load' used to describe degree of weapon readiness) removed. The 
remaining incident records were then subjected to the inclusion and exclusion criteria detailed in Table 1.

\section{INSERT TABLE 1 HERE}

All TOOCS code fields (e.g. 'body location', 'mechanism') in the included injury records were then cleaned by comparing allocated TOOCS codes with narrative description field data. When discrepancies were identified, precedence was given to the narrative description field, as descriptions provided by those reporting the incidents were considered more detailed and accurate than data entered by a third party using a finite coding system. Data were then recoded into the TOOCS data fields or amended TOOCS data fields.

To increase data accuracy, brevity and sensitivity, two TOOCS fields were recoded after the dataset was refined to include only injuries occurring during load carriage, these being body location and mechanism of injury. Common body locations were grouped and generalised to region. For example, following review of the narrative description fields, 'neck and shoulder', 'neck bones, muscles and tendons', 'neck and trunk', and 'shoulder' were all coded under 'neck and shoulder'. This process was performed to improve data accuracy by removing some ambiguity over precise body locations of injuries. Overall, body locations were reduced from 32 categories to 17 categories in the OHSCAR data set. The original TOOCS body location categories and the corresponding modified body location data categories used in this study are tabulated in Table 2.

\section{INSERT TABLE 2 HERE}


Several original TOOCS mechanisms of injury categories were also merged. Although this change decreased data specificity, merging the 'mechanism' categories into broader categories increased data accuracy and removed ambiguity. As an example, a data descriptor stating that a soldier had fallen with a pack and complained of an ankle injury was classified as a 'fall from height'. By classifying incidents such as that example in a general 'fall' classification, uncertainty as to whether the fall was on the same level or from a height (which the available data could not elucidate) was removed. The original and the modified TOOCS mechanisms of injury categories used in this study are tabulated in Table 3.

\section{INSERT TABLE 3 HERE}

Ethics approval for the research was granted by the Australian Defence Human Research Ethics Committee (Protocol: 569-09), and the Behavioural and Social Sciences Research Ethics Committee of The University of Queensland (Project number: 2009001820).

\section{RESULTS}

A total of 1,954 injury records were extracted from the OHSCAR database using the predefined search terms, for the chosen period of 1 January 2009 to 31 December 2010. Manual cleaning removed 16 repeated entries and 112 records for persons from an unknown military service. Implementation of the planned inclusion and exclusion criteria to ensure that only load carriage related injury records were retained resulted in a total of 404 such records being retained. These 404 load carriage related injury records represented $8 \%$ of the total 5188 OHSCAR injury records that represented ARA injuries sustained between 01 January 2009 and 31 December 2010 which resulted from body stressing, these being injuries caused 
by physical stress to the body.

Among the 404 load carriage injuries reported on the OHSCAR database, $10 \%$ were sustained by female soldiers and $90 \%$ were sustained by male soldiers. This ratio is commensurate with the gender ratio across the ARA population as a whole (2007-2009), being $10 \%$ female and $90 \%$ male (13). In addition, $91 \%$ were classified as minor injuries, $1 \%$ as incapacity, and $7 \%$ as a serious personal injury (patient needed emergency treatment by a registered medical practitioner or treatment in a hospital as a casualty).

The distribution of these injuries, by body sites, is shown in Figure 1 . The back was the leading site of injury (23\%) followed by the ankle, knee, and neck and shoulder. Fifty-seven percent of the back injuries reported were specifically noted to be lower back injuries, and these lower back injuries constituted $13 \%$ of all included load carriage injuries. When common body sites were aggregated, $56 \%$ of injuries were noted to affect the lower limbs, $26 \%$ affected the back, and $13 \%$ were to the upper limbs. In addition, $3 \%$ were to the pelvis, $1 \%$ to both the head and abdominal region and less than $1 \%$ was to the upper torso.

\section{INSERT FIGURE 1 HERE}

Numerous inconsistencies between the TOOCS-coded 'nature of injury' data items and associated narrative description fields were identified in the OHSCAR dataset. Furthermore, the detail of information provided in the narrative description fields was insufficient to enable 'recoding' of the data. As an example, one entry, which was TOOCS-coded as a fracture, had the narrative description field report that the pain in the patient's legs dispersed after an hour and the member continued the activity. That incident was classified as a minor injury caused 
by muscular stress. The majority of the TOOCS 'nature of injury' data were excluded from further review on the basis that the results would possess limited reliability. One reliable data subset could however be retrieved, that being for foot blisters, which accounted for $54 \%$ of foot injuries and $5 \%$ of load carriage injuries overall.

The reported mechanisms of load carriage injury incidents in records extracted from the OHSCAR database are shown in Table 4, using modified categories. Among the reported load carriage injuries, 77\% of ankle injuries were classed as 'rolled' or 'twisted' ankles due to misstep and tripping. Of these injuries, 78\% listed 'fall' as the principle mechanism of injury. All of the 'rubbing and chafing' injuries were foot blisters and likewise all of the heat-related injuries (7\% of all injuries and $31 \%$ of serious personal injuries) were reportedly caused by 'exposure to environmental heat' during a load carriage event.

\section{INSERT TABLE 4 HERE}

Marching was reported as the most common activity being conducted at the time when load carriage injuries occurred (62\%), followed by patrolling (13\%), combat training (12\%) and Physical Training (PT) (6\%). Of the remaining injuries, 5\% were attributed to manual handling, and $1 \%$ to boarding a vehicle and walking, respectively. 'Unknown' or 'other' activities constituted $1 \%$ of the activities being conducted at the time of injury.

\section{DISCUSSION}

In this study soldiers reported that ARA load carriage activities had caused them injury. The majority of these load carriage injuries involved either the lower limb or back. Marching activities were the leading activities being performed at the time that load carriage injuries 
occurred, and muscular stress was identified as the mechanism of injury for over half of reported load carriage injuries.

The distributions of body sites of injury corresponded with injury body site findings within both specific load carriage studies $(14,15)$ and studies of general military training $(16,17)$, suggesting consistency across contexts of load carriage, as well as across time (i.e. single load carriage event against a two-year profile). In the current study, the lower limbs were attributed with the highest proportions (56\%) of reported injuries. A high proportion of lower leg injuries is consistent with findings of previous studies of single load carriage events (14, 15), of military personnel in general (16), of ADF personnel specifically (18), and of recreational hikers (19).

In the aggregated injury body site data, the back was associated with the second highest proportion of reported injuries, presenting as the leading specific site of injury (followed by the ankle), with $57 \%$ of back injuries (13\% of all injury cases) affecting the lower back. Given the biomechanical impacts of load carriage on the spine, such as increased lumbar compression and shear forces, changes to thoraco-pelvic rhythm and increased forward lean $(3,20)$, the high proportion of lower back injuries was not unexpected.

Differences between the results of the current study and those of other injury studies $(14,15$, 19) are also evident, most notably in the proportions of ankle injuries, foot blisters, and environmental injuries recorded. Ankle injuries in this study represented $16 \%$ of all reported injuries, with $77 \%$ of these injuries described as 'rolled' or 'twisted' ankles in the OHSCAR free text narratives. Conversely, studies by Knapik, et al. (14) and Reynolds, et al. (15), reporting injuries sustained during a specific load carriage event, observed lower proportions 
of ankle injuries. In the study by Knapik, et al. (14), $6 \%$ of all injuries were determined to be ankle and knee sprains. Similarly, Reynolds, et al. (15) reported 5\% of all injuries to be injuries to the ankle. From a non-military context, $28 \%$ of all injuries reported by New Zealand hikers in the study by Lobb (19) were to the ankle. A potential reason for these differences in injury site proportions comes from the contextual environments of the studies. Whereas the studies of Knapik, et al.(14) and Reynolds, et al. (15) observed load carriage on formed roads or dirt paths during a single marching event, the results of the current study captured incidents across all terrains during events ranging from endurance marching to patrolling. The importance of terrain and task type in determining ankle injury rates is evident by the fact that $77 \%$ of the ankle injuries observed in the current study were attributed to tripping as the mechanism of injury.

The available literature on soldier load carriage identifies foot blisters as the primary concern for military marching (21). In the current study, 5\% of injury records were due to foot blisters. These proportions of foot blister injuries are similar to those observed by Lobb(19) (6.8\%) although notably lower than the proportions reported by Knapik, et al.(14, 22) and Reynolds, et al. (15), these being between $32 \%$ and $48 \%$ of all reported injuries. Several potential reasons for these differences in blister proportions exist, including reporting practices, differences in the nature of load carriage activities and study methods, improvements over time in boot design, and additional risk factors. Data capture in the current study was achieved through OHSCAR injury surveillance, in turn based on OHS incidents. As such, not all injuries may have been reported, with some soldiers suffering from foot blistering perhaps self-managing the incident without completing an injury report form. Conversely, the study methods of Knapik, et al. $(15,23)$ and Reynolds, et al. (15) provided a 
greater opportunity to capture data on blister injuries, with their studies including active medical assessments following the load carriage event.

The notable number of environmental heat-related injuries (hyponatremia as an example) observed in the current study was unexpected. No other studies were found in the literature to have reported this injury type associated with load carriage. Although accounting for only $7 \%$ of all reported load carriage related injuries, heat-related injuries accounted for $31 \%$ of all reported serious personal injuries in the data captured. With heat-related injuries having previously caused fatalities in military personnel in the ARA (23) and foreign defence forces (24), this finding is of particular concern.

Although muscular stress was identified in the current study as the leading mechanism of injury during load carriage $(62 \%)$, several other mechanisms were associated with injuries identified in this study. In the $7 \%$ of injuries that constituted heat-related injuries, all 28 cases listed exposure to environmental heat as the causal mechanism. However, the literature suggests other mechanisms which contribute to heat-related injuries, such as metabolic heat production and clothing insulation, each of which can be a causal factor (25). As the OHSCAR database can list only a single mechanism of injury, these findings on causes of heat injury from that data source must be interpreted with caution.

Among the 5\% of injuries reportedly caused by rubbing and chafing, the injury type sustained in all of these 21 cases was friction blisters to the feet. These results concur with the mechanisms of injury associated with foot blisters reported in the literature (21). Finally, of the $21 \%$ of injuries reportedly caused by a fall in the OHSCAR data, 53\% were ankle injuries. Of these ankle injuries, 78\% were described as 'rolled' or 'twisted' ankles reportedly 
caused by falls. The findings in this study suggest the potential consequences of the findings of Park, et al. (26), who observed an increasing risk of trips and falls associated with obstacle negotiation when carrying increasing loads.

Marching activities could be completed as part of field training exercises or PT and while narrative description fields did often indicate the circumstances in which the marching activity was being conducted, this was not always the case. The next most common activity identified as causing injuries during load carriage was 'patrolling, constituting $13 \%(\mathrm{n}=51)$ of OHSCAR load carriage injury records over the data capture period. Conversely, PT was identified in $6 \%(n=24)$ of these injury records as the activity performed at the time of injury.

Apart from differences in the amounts of time that soldiers were exposed to the two activities (PT sessions typically shorter in duration than a military patrol), two other potential reasons for a higher frequency of injury occurring during patrolling include differences in the respective load carriage contexts between the two activities and the role of Physical Training Instructors (PTI). Previous research in this population noted that ARA soldiers typically carry heavier loads during field exercises, and as such while patrolling, when compared to PT (27). In addition, the terrain typical of PT sessions is over roads as opposed to the bushland traversed when patrolling on a field exercise (27). Both the heavier loads and the more challenging terrain may have induced the higher frequency of injuries reported for patrolling. The differences in terrain may also account for the higher frequency of ankle injuries reported for field training exercise in general than for PT, given that uneven terrain is a risk factor for ankle injury (28). As such, with PT designed to prepared the soldier to carry load during military exercises and operations (29), inadequate preparation of the soldiers during PT for load carriage tasks may be a cause of the higher proportion of field injuries. Consequently, 
when soldiers are required to carry heavier loads while patrolling they might be more susceptible to injury, resulting in the higher frequency of injuries reported as occurring during patrolling.

As a final thought, PT lessons are commonly conducted by PT Instructor (PTI) staff trained in the safe conduct of physical activity. PTI staff are trained to monitor participants for signs of fatigue, illness and injury - monitoring that forms part of the ARA's injury prevention strategy for injuries sustained during physical activity(18). As such, PTIs may have anticipated and prevented some instances of potential load carriage injuries during PT sessions.

\section{LIMITATIONS}

Although the OHSCAR data was useful in capturing the current load carriage injury context, two key limitations are presented: inability to accurately determine exposure rates, and difficulty in accurately identifying causal factors. First, based on OHSCAR data, reported injuries sustained during load carriage activities constituted $8 \%$ of all ARA body stressing injuries over a 2-year period. Unfortunately, this figure does not take into account respective activity exposure rates. Second, there is potential for load carriage activities to be causal factors in the 'deformation' of tissue, where tissue is degraded and weakened, yet not the 'yield point' where the injury occurs (30) with the injury presenting during another activity or task. On this basis, the results reported in this study may under-represent load carriage related injuries in the ARA.

\section{CONCLUSION}


This study suggests that load carriage is a substantial source of injury risk to the Australian Army soldier. Commensurate with historical records and studies in other allied militaries, the lower limbs and back were reported to be the primary sites of injury associated with load carriage. In contrast, however, this study identified a concerning number of heat-related injuries reportedly caused by 'exposure to environmental heat' during a load carriage event, and these had not been reported in previous studies.

In addition, injuries reportedly sustained during field training exercises were more numerous than those reportedly sustained during PT. Other factors notwithstanding, a potential cause for this higher number of injuries sustained during field training may be that PT fails to adequately prepare soldiers, in both load weight and load carriage context, for load carriage tasks, like patrolling required during field training exercises and on operations.

\section{CONFLICT OF INTEREST}

'Authors, Orr, Johnson, Coyle and Pope declare that they have no conflict of interest' 


\section{REFERENCES}

1. $\quad$ Orr R. The History of the Soldier's Load. Australian Army Journal. 2010;VII(2):67-88.

2. Knapik JJ, Reynolds KL, Harman E. Soldier load carriage: historical, physiological, biomechanical, and medical aspects. Mil Med. 2004;169(1):45-56.

3. Meakin JR, Smith FW, Gilbert FJ, Aspden RM. The effect of axial load on the sagittal plane curvature of the upright human spine in vivo. J Biomech. 2008;41(13):2850-4.

4. Harman E, Han K-H, Frykman PN. Load-speed interaction effects on the biomechanics of backpack load carriage. RTO Meeting Proceedings 56: Soldier Mobility: Innovations in Load Carriage System Design and Evaluation; Kingston, Canada: Research and Technology Organisation/North Atlantic Treaty Organization; 2000.

5. Wright A. Smart Vests Take Pressure Off troops. National Defense. 2009;94(672):19.

6. Orr RM, Pope R, Johnston V, Coyle J. Load carriage and its force impact. Australian defence force journal: Journal of the Australian profession of arms. 2011;185:52-63.

7. Butler NL. Injury Prevention as a Combat Multiplier. Carlisle Barracks, PA: U.S. Army War College, 2008.

8. Lee JWI. A Greek Army on the March: Soldiers and Survival in Xenophon's Anabasis. New York: Cambridge University Press; 2007.

9. Lothian NV. The load carried by the soldier. J R Army Med Corps. 1921;38:9-24, 241-63, 342 $51,448-58$.

10. Mayville WC. A Soldier's Load. Infantry. 1987;Jan/Feb 87(25 - 28).

11. Department of Defence. Incidence Capture. Department of Defence (AUST); 2011 [31 Jan 2011]; Available from: http://www.defence.gov.au/dpe/ohsc/Incidents/default.htm\#guidance.

12. Australian Safety and Compensation Council. Type of Occurence Classification System: Australian Safety and Compensation Council, Canberra; 2008.

13. Khosa R. Australian Defence Almanac 2010-2011: Australian Strategic Policy Institute; 2010.

14. Knapik JJ, Reynolds KL, Staab J, Vogel JA, Jones B. Injuries associated with strenuous road marching. Mil Med. 1992;157(2):64-7.

15. Reynolds KL, White J, Knapik JJ, Witt C, Amoroso P. Injuries and risk factors in a 100-mile (161-km) infantry road march. Preventative Medicine. 1999;28(2):167-73.

16. Jennings BM, Yoder LH, Heiner SL, Loan LA, Bingham MO. Soldiers With Musculoskeletal Injuries. Journal of Nursing Scholarship. 2008;40(3):268-74.

17. O'Connor F. Injuries during Marine Corps officer basic training. Mil Med. 2000;165(7):515-20.

18. Defence Health Services Branch. ADF Health Status. Defence Health Services Branch: Department of Defence. 2000.

19. Lobb B. Load carriage for fun: a survey of New Zealand trampers, their activities and injuries. Appl Ergon. 2004;35(6):541-7.

20. Attwells R, Birrell SA, Hooper RH, Mansfield NJ. Influence of carrying heavy loads on soldier's posture, movements and gait. Ergonomics. 2006;49(14):1527-37.

21. Knapik JJ, Reynolds KL, Duplantis KL, Jones B. Friction Blisters: Pathophysiology, Prevention and Treatment. Sports Medicine. 1995;20(3):136-47.

22. Knapik JJ, Reynolds K, Barson J. Influence of an antiperspirant on foot blister incidence during cross-country hiking. Journal of the American Academy of Dermatology. 1998;39(2):202-6.

23. Rudzki SJ. Lessons Learnt From A Heat Stroke Death: 704: May 28 9: 30 AM-9: 45 AM. Medicine \& Science in Sports \& Exercise. 2009;41(5):56.

24. Carter III R, Cheuvront SN, Williams JO, Kolka MA, Stephenson LA, Sawka MN, et al. Epidemiology of hospitalizations and deaths from heat illness in soldiers. Medicine \& Science in Sports \& Exercise. 2005;37(8):1338.

25. Goldman RF. Introduction to heat-related problems in military operations, in. Medical Aspects of Harsh Environments Volume 1: Office of the Surgeon General, United States Army; 2001. p. 3-49. 
26. Park K, Hur P, Rosengren KS, Horn GP, Hsiao-Wecksler ET. Effect of load carriage on gait due to firefighting air bottle configuration. Ergonomics. 2010;53(7):882-91.

27. Orr R. The Australian Army load carriage context: A challenge for defence capability. Annual Military Pharmacy Specialist Interest Group conference Brisbane: Australia2012.

28. Chan K, Yuan Y, Li C, Chien P, Tsang G. Sports causing most injuries in Hong Kong. British Journal of Sports Medicine. 1993;27(4):263.

29. Orr R, Pope R, Johnston V, Coyle J. Load carriage: Minimising soldier injuries through physical conditioning-A narrative review. Journal of military and veterans' health. 2010;18(3):31-8.

30. Nordin M, Frankel VH. Basic Biomechanics of the Musculoskeletal System. 3rd ed: Lippincott, Williams \& Wilkins; 2001. 
Table 1: OHSCAR Injury data inclusion and exclusion criteria

\begin{tabular}{|c|c|c|}
\hline Descriptor & Inclusion Criteria & Exclusion Criteria \\
\hline Service Type & Australian Regular Army & $\begin{array}{l}\text { Cadets } \\
\text { Army Reserve } \\
\text { Navy } \\
\text { Air force } \\
\text { Defence civilian }\end{array}$ \\
\hline Incident Description & $\begin{array}{l}\text { Injury first experienced during a load } \\
\text { carriage event, immediately after a } \\
\text { load carriage event, or the day } \\
\text { following a load carriage event, with } \\
\text { no indication of intervening activity }\end{array}$ & $\begin{array}{l}\text { Load carriage identified but injury } \\
\text { associated with other mechanisms (e.g. } \\
\text { running) }\end{array}$ \\
\hline Casualty type & $\begin{array}{l}\text { Serious personal injury } \\
\text { Incapacity } \\
\text { Minor injury }\end{array}$ & $\begin{array}{l}\text { Exposure }^{\mathrm{a}} \\
\text { Dangerous occurrence } \\
\end{array}$ \\
\hline
\end{tabular}


Table 2: Original OHSCAR Bodily Location Classifications and the Reclassifications for the Current Program of Research

\begin{tabular}{|c|c|}
\hline OHSCAR Classifications & Revised Classification \\
\hline $\begin{array}{l}\text { Cranium } \\
\text { Eye }\end{array}$ & Head \\
\hline $\begin{array}{l}\text { Neck and Shoulder } \\
\text { Neck bones, muscles, tendons } \\
\text { Neck and trunk } \\
\text { Shoulder }\end{array}$ & Neck and shoulder \\
\hline $\begin{array}{l}\text { Chest } \\
\text { Upper back }\end{array}$ & Upper Torso \\
\hline $\begin{array}{l}\text { Upper limb-multiple locations } \\
\text { Upper limb-unspecified }\end{array}$ & Upper limb \\
\hline $\begin{array}{l}\text { Hand } \\
\text { Fingers }\end{array}$ & Hand \\
\hline $\begin{array}{l}\text { Abdomen } \\
\text { Abdomen-other and multiple }\end{array}$ & Abdome \\
\hline $\begin{array}{l}\text { Lower back } \\
\text { Back-unspecified } \\
\text { Back-other and multiple } \\
\text { Trunk - multiple locations }\end{array}$ & \\
\hline Hip & Hip \\
\hline $\begin{array}{l}\text { Lower leg } \\
\text { Lower limb - multiple locations }\end{array}$ & $\begin{array}{l}\text { Lower limb - general } \\
\text { Lower limb - multiple locations }\end{array}$ \\
\hline Upper leg & Thigh \\
\hline Knee & Knee \\
\hline Ankle & Ankle \\
\hline $\begin{array}{l}\text { Foot } \\
\text { Toes }\end{array}$ & Foot \\
\hline Other specific multiple locations & Multiple \\
\hline Trunk and limbs & Back/Lower Limb \\
\hline $\begin{array}{l}\text { Circulatory system } \\
\text { Digestive system } \\
\text { Other multiple systemic condition } \\
\text { Unspecified systemic condition }\end{array}$ & Systemic \\
\hline
\end{tabular}


Table 3: Original OHSCAR Mechanism of Incidence Classifications and the Reclassifications for the Current Program of Research

\begin{tabular}{|c|c|}
\hline OHSCAR Classifications & Revised Classifications \\
\hline Being hit by moving objects & Contact with moving or stationary object \\
\hline \multicolumn{2}{|l|}{ Hitting stationary objects } \\
\hline Being trapped between stationary and moving object & Being trapped between stationary and moving object \\
\hline Exposure to environmental heat & Exposure to environmental heat \\
\hline Falls from a height & Fall \\
\hline \multicolumn{2}{|l|}{ Falls on the same level } \\
\hline $\begin{array}{l}\text { Muscular stress while handling objects other than lifting, } \\
\text { carrying or putting down }\end{array}$ & Muscular stress while lifting carrying or putting \\
\hline \multirow{2}{*}{\multicolumn{2}{|c|}{$\begin{array}{l}\text { Muscular stress while lifting carrying or putting down } \\
\text { objects } \\
\text { Muscular stress with no objects being handled }\end{array}$}} \\
\hline & \\
\hline Other and multiple mechanisms of injury & Other and multiple mechanisms of injury \\
\hline Rubbing and chafing & Rubbing and chafing \\
\hline Stepping kneeling or sitting on objects & Stepping kneeling or sitting on objects \\
\hline Unspecified mechanisms of injury & Unspecified mechanisms of injury \\
\hline
\end{tabular}


Table 4: OHSCAR-reported mechanisms of load carriage injuries for the period 2009 and 2010

\begin{tabular}{lc}
\hline Mechanism of Load Carriage Injuries & Number of reported injuries \\
\hline Muscular stress & 251 \\
Fall & 85 \\
Exposure to environmental heat & 28 \\
Rubbing and chafing & 21 \\
Stepping kneeling or sitting on objects & 9 \\
Unspecified mechanisms of injury & 3 \\
Contact with moving or stationary object & 4 \\
Other and multiple mechanisms of injury & 2 \\
Being trapped between stationary and moving object & 1 \\
\hline TOTAL & 404 \\
\hline
\end{tabular}


Figure 1: Histogram of OHSCAR-reported ARA load carriage injuries (2009-2010) by body site.

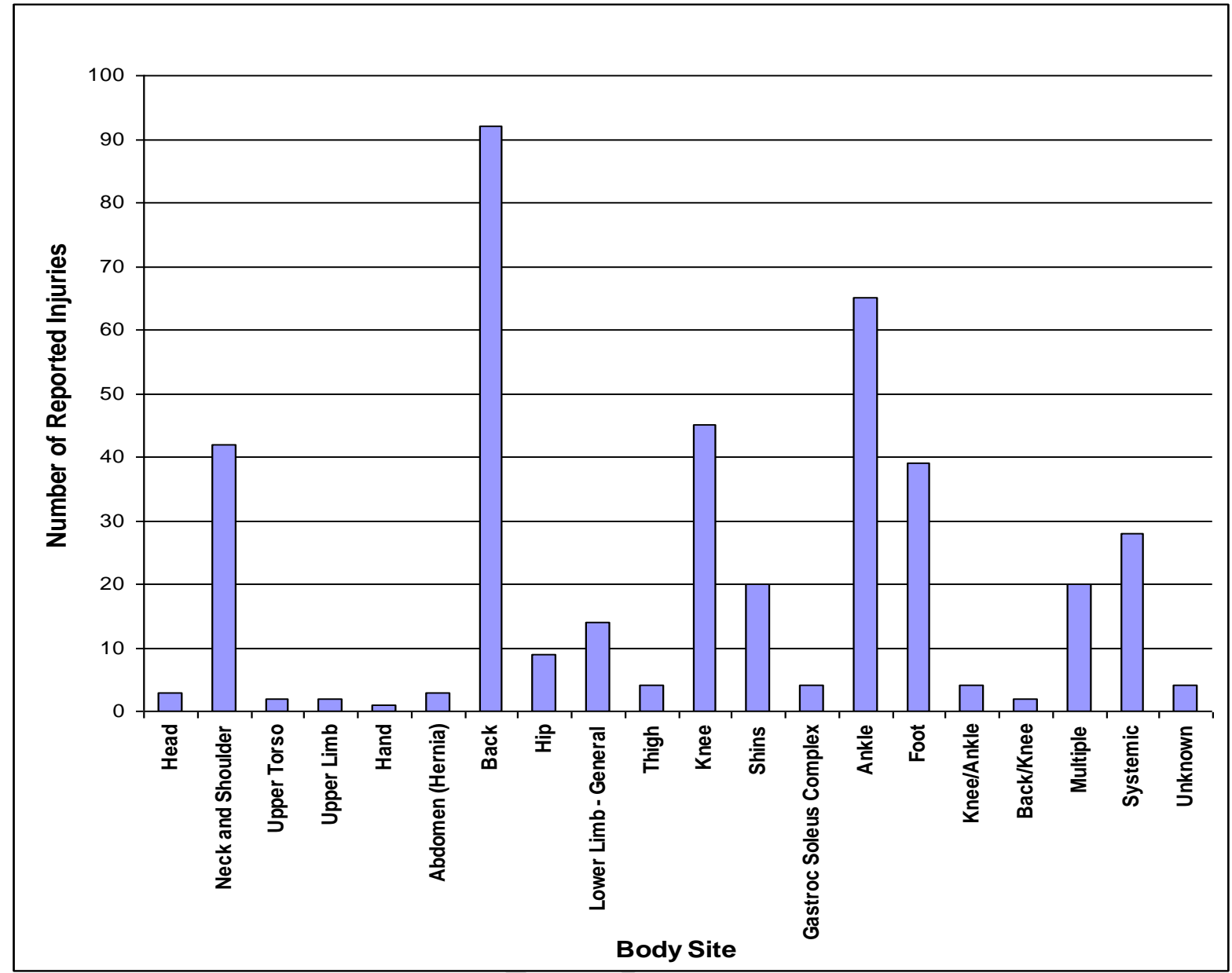

